\title{
Relationship between polyunsaturated fatty acid composition in serum phospholipids, systemic low-grade inflammation, and glycemic control in patients with type 2 diabetes and atherosclerotic cardiovascular disease
}

Malgorzata Poreba ${ }^{1 \dagger}$, Pawel Rostoff ${ }^{1 \dagger}$, Aleksander Siniarski ${ }^{1}$, Magdalena Mostowik',

Renata Golebiowska-Wiatrak ${ }^{1}$, Jadwiga Nessler ${ }^{1}$, Anetta Undas ${ }^{2}$ and Grzegorz Gajos ${ }^{1 *}$ (D)

\begin{abstract}
Background: There are inconsistent data about the role of serum phospholipid fatty acid composition in patients with type 2 diabetes (T2DM) and atherosclerotic cardiovascular disease (ASCVD). The aim of the study was to investigate the relationship between serum phospholipid fatty acid composition, systemic low-grade inflammation, and glycemic control in high-risk T2DM patients.
\end{abstract}

Methods: Seventy-four patients (26\% women, mean age $65.6 \pm 6.8$ years) with T2DM (median diabetes duration 10 years) and documented ASCVD (74 with coronary artery disease, 26 with peripheral arterial disease) were enrolled in the study. Baseline $\mathrm{HbA}_{1 \mathrm{c}}$ was estimated using turbidimetric inhibition immunoassay. According to the median value of $\mathrm{HbA}_{1 \mathrm{c}}$ the patients were grouped into those with $\mathrm{HbA}_{1 \mathrm{c}}<7.0 \%(<53 \mathrm{mmol} / \mathrm{mol})(\mathrm{n}=38)$ and those with $\mathrm{HbA}_{1 \mathrm{c}} \geq 7.0 \%$ ( $\left.\geq 53 \mathrm{mmol} / \mathrm{mol}\right)(\mathrm{n}=36)$. Serum phospholipid fatty acids were measured with gas chromatography.

Results: Patients with $\mathrm{HbA}_{1 c} \geq 7.0 \%$, compared with those with $\mathrm{HbA}_{1 c}<7.0 \%$ had similar composition of saturated and monounsaturated fatty acids in serum phospholipids, but had higher concentrations of linoleic acid (LA) and higher n-6/n-3 polyunsaturated fatty acid (PUFA) ratio as well as lower levels of eicosapentaenoic acid (EPA), total $n-3$ PUFAs, and the EPA/arachidonic acid ratio. We found that $L A(r=0.25 ; p=0.03)$ and $n-6 / n-3$ PUFA ratio ( $r=0.28$; $p=0.02$ ) were positively correlated with $\mathrm{HbA}_{1 c}$. Multivariate logistic regression analysis showed that $n-6 / n-3 \mathrm{PUFA}$ ratio, hsCRP and T2DM duration were independent predictors of worse glycemic control in patients with T2DM and ASCVD.

Conclusions: This study showed that glycemic control in high-risk T2DM patients with ASCVD was significantly associated with unfavorable serum phospholipid n-6/n-3 PUFA ratio and greater systemic inflammation.

Keywords: Cardiovascular disease, Atherosclerosis, Type 2 diabetes, Glycemic control, Inflammation, Fatty acids

\footnotetext{
*Correspondence: grzegorz.gajos@uj.edu.pl

${ }^{\dagger}$ Malgorzata Poreba and Pawel Rostoff contributed equally to this work

${ }^{1}$ Department of Coronary Disease and Heart Failure, Faculty of Medicine,

Jagiellonian University Medical College, The John Paul II Hospital, 80

Pradnicka Street, 31-202 Kraków, Poland

Full list of author information is available at the end of the article
} 


\section{Background}

Cardiovascular diseases are the main complications of type 2 diabetes mellitus (T2DM), accounting for approximately two-thirds of deaths in T2DM patients [1-4]. The underlying mechanisms linking T2DM with atherosclerotic cardiovascular disease (ASCVD) remain not fully understood. There is strong evidence that classic risk factors do not explain the higher risk of ASCVD in T2DM patients [5].

Multiple pathophysiologic processes may contribute to ASCVD in T2DM including hyperglycemia, hypoglycemia, insulin resistance or hyperinsulinemia, dyslipidemia, chronic low-grade inflammation, oxidative stress, endothelial dysfunction, vascular calcification, and hypercoagulability [4-11]. Numerous experimental and clinical studies have shown the close relationship between dysglycemia and increased risk for ASCVD, with an estimated $11-16 \%$ increase in cardiovascular events for every $1 \%$ increase in glycated hemoglobin $\left(\mathrm{HbA}_{1 \mathrm{c}}\right)$ level [4]. It has been shown that $\mathrm{HbA}_{1 \mathrm{c}}$ levels of $\geq 7.0 \%(\geq 53 \mathrm{mmol} / \mathrm{mol})$ were associated with unfavorable cardiovascular outcomes in T2DM patients with established atherosclerosis [12].

Epidemiological studies have demonstrated that serum fatty acid (FA) profile is an independent risk factor for ASCVD [5, 13]. Much evidence has been accumulated indicating that dietary or blood FA composition was significantly associated with impaired endothelial function, systemic inflammation, oxidative stress, $\beta$-cell dysfunction, and insulin resistance [14]. It has been also demonstrated that serum/plasma FA profiles are related to an increased risk of T2DM and its macrovascular complications [14].

Long-chain polyunsaturated fatty acids (PUFAs) and their derivatives can modulate many metabolic and inflammatory pathways in diabetic and nondiabetic subjects [15-19]. Epidemiological evidence has indicated that populations with high fish consumption had less risk of diabetes and ASCVD [20]. Although beneficial effects of PUFAs have been widely documented, the results of ORIGIN (Outcome Reduction with Initial Glargine Intervention) study, the world's longest and largest randomized clinical trial in T2DM and prediabetes, showed that n-3 PUFA supplementation did not affect the risk of death from cardiovascular causes in T2DM patients [21]. Thus, the recently published science advisory from the American Heart Association does not recommend supplementation with $\mathrm{n}-3$ PUFAs for individuals with T2DM to prevent coronary artery disease (CAD) [20]. On the other hand, the treatment with n-3 PUFA supplements seems to be reasonable for the secondary prevention of CAD deaths among patients with prior CAD [20].

There are limited and inconsistent data about the role of serum phospholipid FA composition in the pathophysiology of T2DM and diabetes-related ASCVD. In addition, very little is known regarding associations of dysglycemia with serum FA profiles and chronic inflammation in T2DM patients with documented ASCVD.

Therefore, the aim of the present study was to investigate the relationship between FA composition in serum phospholipids, systemic low-grade inflammation, and glycemic control in patients with T2DM and established ASCVD.

\section{Methods \\ Patients}

The study design and population sampling are described in detail elsewhere [22]. In brief, we assessed 126 following T2DM patients with a history of coronary artery disease (CAD) and/or peripheral artery disease (PAD). Exclusion criteria were the same as in our previous study [22]. Finally, 74 patients with T2DM and established $\mathrm{CAD}$ and/or PAD were enrolled. The median duration of diabetes was 10 (interquartile range [IQR], 6-15) years. Diabetic patients were grouped according to the median value of $\mathrm{HbA}_{1 \mathrm{c}}$ into those with $\mathrm{HbA}_{1 \mathrm{c}}<7.0 \%(<53 \mathrm{mmol} /$ mol) ( $\mathrm{n}=38$ individuals) and those with $\mathrm{HbA}_{1 \mathrm{c}} \geq 7.0 \%$ ( $\geq 53 \mathrm{mmol} / \mathrm{mol})$ ( $\mathrm{n}=36$ patients).

This study was performed according to the Helsinki Declaration with the approval of the Ethics Committee of the Jagiellonian University Medical College (No: KBET/190/B/2012). Informed consent was obtained from all individual participants included in the study.

\section{Blood sampling and laboratory measurements}

Fasting blood samples were obtained between 8 and 10 a.m. after overnight fast. Samples were processed 30-60 min after blood collection. Then serum samples were stored at $-70{ }^{\circ} \mathrm{C}$ until further analysis. Routine blood tests, such as complete blood count, lipid profile, serum creatinine were carried out by automated laboratory techniques. $\mathrm{HbA}_{1 \mathrm{c}}$ was estimated using turbidimetric inhibition immunoassay (TINIA).

Serum levels of saturated (lauric acid, C12:0; myristic acid, C14:0; palmitic acid, C16:0; stearic acid, C18:0; lignoceric acid C24:0) and unsaturated FAs: $\mathrm{n}-7$ (palmitoleic acid, C16:1), n-9 (oleic acid, C18:1), n-3 (alpha-linolenic acid-ALA, C18:3; eicosapentaenoic acid-EPA, C20:5; docosahexaenoic acid-DHA, C22:6) and n-6 (linoleic acid-LA, C18:2; eicosadienoic acid C20:2; arachidonic acid-AA, C20:4) were measured with gas chromatography (Agilent Technologies 6890N Network GC Systems, Wilmington, De., USA). The detailed methods were described previously [22]. A concentration of serum FAs of phospholipids fraction was expressed in $\mu \mathrm{mol} / \mathrm{l}$.

High-sensitivity C-reactive protein (hsCRP) was measured by latex nephelometry (Dade Behring, Marburg, Germany). The serum levels of interleukin-6 (IL-6) and tumor necrosis factor $\alpha$ (TNF $\alpha$ ) were evaluated by ELISA (R\&D Systems, USA). 


\section{Statistical analysis}

Categorical variables were presented as numbers and percentages. Continuous variables were expressed as mean \pm standard deviation (SD) or median and interquartile range (IQR). Differences between the groups were compared using the Student's $t$ test for normally distributed variables. The Mann-Whitney U test was used for non-normally distributed continuous variables. Data normality was verified by the Shapiro-Wilk test. Categorical variables were compared by the Fisher's exact test or by the Pearson's $X^{2}$ test, when appropriate. The Spearman's rank correlation coefficient was calculated to measure monotonic trend between two variables. Stepwise logistic regression analysis was performed for determining the independent predictors of poor glycemic control in the study patients. The calibration and discrimination of the developed model were assessed using the Hosmer-Lemeshow statistic and the area under the receiver operating characteristic curve (AUC), respectively. Twosided $\mathrm{p}$ values $<0.05$ were considered statistically significant. All calculations were made using the STATISTICA version 12.0 PL software package (StatSoft, Inc., Tulsa, Oklahoma).

\section{Results}

\section{Baseline characteristics}

The baseline characteristics of the study patients, including comorbidities and medications are shown in Table 1. Of the total population, 66.2, 97.3, 67.6\%, were obese, hypertensive, and dyslipidemic, respectively. Mean age of the study population was $65.6 \pm 6.8$ years. There were no sex differences in demographic and clinical characteristics.

Patients with worse glycemic control at baseline $\left(\mathrm{HbA}_{1 \mathrm{c}} \geq 7.0 \%\right)$ had significantly longer diabetes duration as compared to those with $\mathrm{HbA}_{1 \mathrm{c}}<7.0 \%$. There was a higher proportion of insulin users among subjects with $\mathrm{HbA}_{1 \mathrm{c}} \geq 7.0 \%$ (Table 1 ).

There were no significant differences in laboratory characteristics between studied groups except for higher $\mathrm{HbA}_{1 \mathrm{c}}$ values and increased hsCRP levels in patients with worse glycemic control (Table 2). In addition, the individuals with $\mathrm{HbA}_{1 \mathrm{c}} \geq 7.0 \%$ had lower baseline concentrations of C-peptide.

\section{Fatty acid composition in serum phospholipids}

Saturated FAs were the largest fraction in serum phospholipids, followed by $n-6$ polyunsaturated, $n-3$ polyunsaturated, and monounsaturated. Among the single FAs, palmitic acid constituted the largest proportion with $31.2 \%$, followed by AA (17.3\%), LA (14.3\%), stearic acid (13.6\%), oleic acid (9.0\%), and DHA (9.0\%).

There were no relevant intergroup differences in the composition of saturated and monounsaturated FAs in serum phospholipids (Table 3). T2DM patients with worse glycaemic control had significantly higher concentrations of LA and higher n- $6 / \mathrm{n}-3$ ratio as compared to diabetic individuals with $\mathrm{HbA}_{1 \mathrm{c}}<7.0 \%$. Furthermore, the study patients with $\mathrm{HbA}_{1 \mathrm{c}} \geq 7.0 \%$ had lower levels of EPA, total n-3 PUFAs, and the EPA/AA ratio (Fig. 1).

\section{Correlations}

We found that LA $(\mathrm{r}=0.25 ; \mathrm{p}=0.03)$ and $\mathrm{n}-6 / \mathrm{n}-3$ ratio $(r=0.28 ; p=0.02)$ were positively correlated with $\mathrm{HbA}_{1 \mathrm{c}}$. No significant correlations were observed with regard to other FAs or ratios. In addition, we found a significant association between $\mathrm{HbA}_{1 \mathrm{c}}$ and hsCRP levels $(\mathrm{r}=0.31 ; \mathrm{p}=0.008)$. There were no relevant associations between systemic inflammatory markers (hsCRP, IL-6 and TNF $\alpha$ ) and serum phospholipid FA composition in T2DM patients with ASCVD.

\section{Univariate and multivariate logistic regression analyses}

Statistically significant predictors of poor glycaemic control $\left(\mathrm{HbA}_{1 \mathrm{c}} \geq 7.0 \%\right)$ in the study population are presented in Table 4. Multivariate logistic regression analysis demonstrated that $n-6 / n-3$ ratio, hsCRP and T2DM duration were independent predictors of worse glycaemic control in our patients. The predictive model showed good cross-validated calibration and discrimination with Hosmer-Lemeshow $\chi^{2}=10.73, p=0.21$ and $\mathrm{AUC}=0.872$, respectively.

\section{Discussion}

To our knowledge, this is the first study to show that a poor glycemic control $\left(\mathrm{HbA}_{1 \mathrm{c}} \geq 7.0 \%\right)$ in high-risk diabetic subjects with ASCVD is associated with decreased levels of EPA, total n-3 PUFAs, and lower EPA/AA ratio in the serum phospholipid fraction. Furthermore, the patients with worse glycaemic control had increased serum concentrations of LA and hsCRP, as well as a higher $n-6 / n-3$ ratio. In multivariate analysis, the $n-6 /$ $\mathrm{n}-3$ ratio was the strongest predictor of poor glycaemic control, followed by serum hsCRP, and T2DM duration. Interestingly, we did not found any relevant intergroup differences in the composition of saturated and monounsaturated FAs in serum phospholipids.

It is well known that FA composition of serum phospholipids reflects dietary FAs intake during the preceding weeks as well as endogenous FAs metabolism, including FA synthesis (de novo lipogenesis) and FA desaturation, elongation, retroconversion, and oxidation [23, 24]. Recently published data indicate that meal frequency may also affect the FA composition of serum phospholipids in patients with T2DM [24].

\section{PUFAs and type 2 diabetes mellitus}

Experimental and clinical studies showed that serum FA composition is abnormal in T2DM patients [13]. A few studies have demonstrated that elevated levels of palmitic 
Table 1 Baseline characteristics of the study population $(n=74)$

\begin{tabular}{|c|c|c|c|c|}
\hline Variable & $n=74$ & $\begin{array}{l}\mathrm{HbA}_{1 \mathrm{c}}<7.0 \% \\
\mathrm{n}=38\end{array}$ & $\begin{array}{l}\mathrm{HbA}_{1 \mathrm{c}} \geq 7.0 \% \\
\mathrm{n}=36\end{array}$ & p value \\
\hline Age (years) & $65.6 \pm 6.8$ & $66.0 \pm 6.7$ & $65.2 \pm 7.1$ & 0.62 \\
\hline Female gender, n (\%) & $26(35.1)$ & $10(26.3)$ & $16(44.4)$ & 0.10 \\
\hline Hypertension, n (\%) & $72(97.3)$ & $37(97.4)$ & $35(97.2)$ & 0.97 \\
\hline Hyperlipidemia, n (\%) & $50(67.6)$ & $24(63.2)$ & $26(72.2)$ & 0.41 \\
\hline Metabolic syndrome, n (\%) & $74(100.0)$ & $38(100.0)$ & $36(100.0)$ & 1.00 \\
\hline Obesity, n (\%) & $49(66.2)$ & $26(68.4)$ & $23(63.9)$ & 0.68 \\
\hline Waist circumference (cm) & $106.5 \pm 9.4$ & $106.7 \pm 9.1$ & $106.2 \pm 9.8$ & 0.83 \\
\hline Body mass index, $\mathrm{kg} / \mathrm{m}^{2}$ & $31.2 \pm 3.6$ & $31.1 \pm 3.0$ & $31.3 \pm 4.1$ & 0.81 \\
\hline Body fat (\%) & $34.1 \pm 8.6$ & $32.9 \pm 7.4$ & $35.4 \pm 9.6$ & 0.23 \\
\hline Visceral fat (\%) & $16.0 \pm 4.7$ & $16.4 \pm 5.0$ & $15.5 \pm 4.2$ & 0.53 \\
\hline Total body water (\%) & $47.6(44.2 ; 49.3)$ & $48.6(44.2 ; 49.3)$ & $47.2(44.0 ; 49.1)$ & 0.45 \\
\hline Muscle mass (kg) & $55.2 \pm 10.4$ & $56.1 \pm 8.6$ & $54.0 \pm 12.7$ & 0.51 \\
\hline \multicolumn{5}{|l|}{ Medical history } \\
\hline T2DM duration (years) & $10(6 ; 15)$ & $9(4 ; 10)$ & $10(7 ; 20)$ & 0.02 \\
\hline CAD, n (\%) & $74(100.0)$ & $38(100.0)$ & $36(100.0)$ & 1.00 \\
\hline PAD, n (\%) & $26(35.1)$ & $10(26.3)$ & $16(44.4)$ & 0.10 \\
\hline Previous MI, n (\%) & $28(37.8)$ & $17(44.7)$ & $11(30.6)$ & 0.21 \\
\hline Previous PCI, n (\%) & $47(65.5)$ & $25(65.8)$ & $22(61.1)$ & 0.68 \\
\hline \multicolumn{5}{|l|}{ Treatment } \\
\hline ASA, n (\%) & $74(100.0)$ & $38(100.0)$ & $36(100.0)$ & 1.00 \\
\hline Clopidogrel, n (\%) & $33(44.5)$ & $16(42.1)$ & $17(47.2)$ & 0.66 \\
\hline Beta blocker, n (\%) & $61(82.4)$ & $32(84.2)$ & 29 (80.6) & 0.68 \\
\hline ACE inhibitor or ARB, n (\%) & $67(90.5)$ & $33(86.8)$ & $34(94.4)$ & 0.26 \\
\hline Nitrate long acting, n (\%) & $11(14.9)$ & $5(13.2)$ & $6(16.7)$ & 0.67 \\
\hline Calcium antagonist, n (\%) & $32(43.2)$ & $15(39.5)$ & $17(47.2)$ & 0.50 \\
\hline Statin, n (\%) & $68(91.9)$ & $34(89.5)$ & $34(94.4)$ & 0.43 \\
\hline Fibrate, n (\%) & $1(1.4)$ & 0 & $1(2.8)$ & 0.30 \\
\hline Diuretic, n (\%) & $22(29.7)$ & $9(23.7)$ & $13(36.1)$ & 0.24 \\
\hline MRA, n (\%) & $9(12.2)$ & $4(10.5)$ & $5(13.9)$ & 0.66 \\
\hline Metformin, n (\%) & $49(66.2)$ & $27(71.1)$ & $22(61.1)$ & 0.37 \\
\hline Sulfonylurea, n (\%) & $31(41.9)$ & $19(50.0)$ & $12(33.3)$ & 0.15 \\
\hline Acarbose, n (\%) & $1(1.4)$ & 0 & $1(2.8)$ & 0.30 \\
\hline DPP-IV, n (\%) & $3(4.1)$ & $2(5.3)$ & $1(2.8)$ & 0.59 \\
\hline Insulin, n (\%) & $32(43.2)$ & $9(23.7)$ & 23 (63.9) & 0.0005 \\
\hline PPI, n (\%) & $22(29.7)$ & $9(23.7)$ & $13(36.1)$ & 0.24 \\
\hline
\end{tabular}

Data are given as number (percentage) for categorical variables and mean ( \pm standard deviation) or median (IQR) for continuous variables Italic values indicate significance of $p$ value $(p<0.05)$

$A C E$ angiotensin-converting enzyme, $A R B$ angiotensin II receptor blocker, $A S A$ acetylsalicylic acid, CAD coronary artery disease, $M I$ myocardial infarction, $M R A$ mineralocorticoid receptor antagonist, $P A D$ peripheral artery disease, $P C l$ percutaneous coronary intervention, $P P I$ proton pump inhibitor, $T 2 D M$ type 2 diabetes mellitus

(16:0), palmitoleic (16:1n-7), and dihomo- $\gamma$-linolenic (20:3n-6) acids and decreased concentrations of LA in both serum phospholipids and cholesterol esters are related to insulin resistance, metabolic syndrome and T2DM [23, 25]. Leeson et al. reported that higher levels of DHA in erythrocyte phospholipids were associated with improved endothelial function, particularly in young men who had some of the features of insulin resistance [15]. It has been also demonstrated that higher n-3 PUFA concentrations in red cell phospholipids were related to increased insulin sensitivity and a more favorable metabolic profile in middle-aged overweight men [26]. Takashi et al. found that T2DM patients with a history of prior myocardial infarction had significantly lower serum levels of EPA and DHA, as well as the EPA/AA and DHA/ AA ratios as compared to diabetic patients without a history of myocardial infarction [16]. 
Table 2 Baseline laboratory investigations $(n=74)$

\begin{tabular}{|c|c|c|c|c|}
\hline Variable & $\mathrm{n}=74$ & $\begin{array}{l}\mathrm{HbA}_{1 \mathrm{c}}<7.0 \% \\
\mathrm{n}=38\end{array}$ & $\begin{array}{l}\mathrm{HbA}_{1 \mathrm{c}} \geq 7.0 \% \\
\mathrm{n}=36\end{array}$ & $p$ value \\
\hline $\mathrm{HbA}_{1 c}(\%)$ & $7.0(6.6 ; 7.5)$ & $6.6(6.5 ; 6.8)$ & $7.5(7.2 ; 8.3)$ & $<0.0001$ \\
\hline Insulin ( $\mu \mid \mathrm{U} / \mathrm{ml})$ & $21.5(14.6 ; 33.6)$ & $19.1(14.6 ; 27.9)$ & $24.4(14.8 ; 38.5)$ & 0.15 \\
\hline C-peptide (ng/ml) & $3.25 \pm 1.40$ & $3.61 \pm 1.47$ & $2.87 \pm 1.24$ & 0.02 \\
\hline $\mathrm{TC}(\mathrm{mmol} / \mathrm{l})$ & $3.86 \pm 0.91$ & $3.69 \pm 0.85$ & $4.04 \pm 0.95$ & 0.10 \\
\hline LDL-C (mmol/l) & $1.91(1.53 ; 2.64)$ & $1.825(1.45 ; 2.51)$ & $1.99(1.63 ; 2.90)$ & 0.22 \\
\hline $\mathrm{HDL}-\mathrm{C}(\mathrm{mmol} / \mathrm{l})$ & $1.24 \pm 0.38$ & $1.28 \pm 0.36$ & $1.21 \pm 0.40$ & 0.75 \\
\hline $\operatorname{Tg}(\mathrm{mmol} / \mathrm{l})$ & $1.35(1.12 ; 1.92)$ & $1.375(0.99 ; 1.91)$ & $1.34(1.14 ; 1.99)$ & 0.57 \\
\hline Creatinine $(\mu \mathrm{mol} / \mathrm{l})$ & $83.7 \pm 22.0$ & $82.9 \pm 17.8$ & $84.5 \pm 25.9$ & 0.77 \\
\hline eGFR (MDRD) (ml/min/1.73 m²) & $78.3(70.0 ; 90.0)$ & $81.8(70.0 ; 90.0)$ & $78.0(64.0 ; 90.0)$ & 0.76 \\
\hline $\operatorname{hsCRP}(\mathrm{mg} / \mathrm{l})$ & $1.54(0.73 ; 2.71)$ & $1.33(0.52 ; 2.43)$ & $1.87(0.85 ; 4.39)$ & 0.02 \\
\hline IL-6 (pg/ml) & $1.99(1.55 ; 2.79)$ & $1.88(1.36 ; 2.28)$ & $2.17(1.64 ; 3.13)$ & 0.09 \\
\hline TNFa (pg/ml) & $1.48(1.28 ; 1.76)$ & $1.43(1.24 ; 1.68)$ & $1.52(1.40 ; 1.79)$ & 0.22 \\
\hline
\end{tabular}

Data are given as number (percentage) for categorical variables and mean ( \pm standard deviation) or median (IQR) for continuous variables

Italic values indicate significance of $p$ value $(p<0.05)$

eGFR (MDRD) estimated glomerular filtration rate calculated by the abbreviated MDRD equation, $H b A_{1 c}$ glycated hemoglobin, $H D L-C$ high-density lipoproteins, $h s C R P$ high-sensitivity C-reactive protein, IL-6 interleukin-6, LDL-C low-density lipoproteins, TC total cholesterol, Tg triglycerides, TNFa tumor necrosis factor alpha

Over the past few decades, numerous investigations provided evidence for beneficial, cardioprotective effects of PUFAs, in particular of the n-3 family [13, 14, 17]. PUFAs, similarly to monounsaturated FAs, may decrease oxidative stress, inflammation and endothelial dysfunction, influence both insulin secretion and insulin resistance, and reduce diabetes risk [14]. In addition, n-3 PUFAs may slow down the progression of pancreatic $\beta$-cell dysfunction [27]. Several epidemiological studies showed that higher serum n-3 PUFA levels may be associated with the lower risk of T2DM [14, 20, 28, 29]. However, data from clinical studies have been conflicting.

It has been demonstrated that $\mathrm{n}-3$ PUFA supplementation improved insulin sensitivity in Asian population of T2DM patients [30]. No benefits were found in Western populations [30, 31]. This finding suggests that the favorable effect of n-3 PUFAs on insulin sensitivity may be affected by ethnicity [31]. On the other hand, Kusunoki et al. found no significant association between HOMA-IR, which was used as a marker of glycemic control, and levels of EPA, DHA, and LA in serum phospholipids of Japanese patients with T2DM [32]. However, the authors did not evaluate the relationship between HOMA-IR and total levels of $n-3$ and $\mathrm{n}-6$ PUFAs as well as the n-6/n-3 ratio [32]. Sawada et al. reported that 6-month EPA supplementation had no effect on plasma glucose, HbA1c, and HOMA-R in newly-diagnosed impaired glucose metabolism patients with $C A D$ [33]. Interestingly, EPA treatment improved postprandial hyperglycemia, insulin secretion ability and hypertriglyceridemia, that might have beneficial effects on endothelial function and oxidative stress [33]. In our last randomized clinical trial, we demonstrated that treatment with $2.0 \mathrm{~g}$ of
EPA-DHA per day for 3 months did not improve glycemic control in high-risk diabetic subjects [22]. We suggested that longer time of administration and/or higher doses of EPA-DHA as well as improvement in oral bioavailability of n-3 PUFAs may ameliorate glycemic control in T2DM patients.

The present study showed that high-risk T2DM patients with intensive glycemic control and $\mathrm{HbA}_{1 \mathrm{c}}$ level $<7.0 \%$ had higher levels of EPA and total n-3 PUFAs, and lower n-6/n-3 ratio, as compared to subjects with poor glycemic control. We hypothesize that the ratio of serum phospholipid n-6 to n-3 PUFAs may play a crucial role in control of glucose metabolism in high-risk T2DM patients. The clinical importance of $n-6 / n-3$ ratio is still poorly understood. A few studies have demonstrated that the dietary $n-6 / n-3$ ratio of $1: 1$ is the most beneficial for metabolic health, whereas it is approximately $15-20: 1$ in the present Western diet [34, 35].

In our study only LA was positively correlated with $\mathrm{HbA}_{1 \mathrm{c}}$. The serum phospholipid LA levels were significantly higher in subjects with worse glycemic control. This finding may at first seem surprising since n-6 PUFAs generally are associated with beneficial health effect. Sartore et al. demonstrated that T2DM subjects have lower LA levels and higher concentrations of highly unsaturated FAs [13]. Moreover, insulin sensitivity increases when saturated FAs are replaced by n-6 PUFAs [14].

It has been also demonstrated that LA in serum phospholipids and cholesterol esters was inversely associated with visceral adipose tissue and trunk fat, both of which are well-known contributors to insulin resistance and metabolic disease [36]. There are evidence that higher 
Table 3 Serum phospholipid fatty acids composition in the study patients

\begin{tabular}{|c|c|c|c|}
\hline Fatty acid & $\begin{array}{l}\mathrm{HbA}_{1 \mathrm{c}}<7.0 \% \\
\mathrm{n}=38\end{array}$ & $\begin{array}{l}\mathrm{HbA}_{1 \mathrm{c}} \geq 7.0 \% \\
\mathrm{n}=36\end{array}$ & $\mathrm{p}$ value \\
\hline \multicolumn{4}{|l|}{ SFAs } \\
\hline $\mathrm{C} 12: 0(\mu \mathrm{mol} / \mathrm{l})$ & $1.73(1.14 ; 2.84)$ & $2.25(1.39 ; 3.31)$ & 0.17 \\
\hline C14:0 ( $\mu \mathrm{mol} / \mathrm{l})$ & $16.20(15.09 ; 18.12)$ & $18.31(14.37 ;$ 20.92) & 0.18 \\
\hline $\mathrm{C} 16: 0(\mu \mathrm{mol} / \mathrm{l})$ & $940.62(833.71 ; 1022.22)$ & $973.60(868.19 ; 1074.23)$ & 0.50 \\
\hline C18:0 ( $\mu \mathrm{mol} / \mathrm{l})$ & $421.96 \pm 92.87$ & $439.14 \pm 96.71$ & 0.44 \\
\hline $\mathrm{C} 24: 0(\mu \mathrm{mol} / \mathrm{l})$ & $24.17(19.31 ; 28.40)$ & $24.695(20.38 ; 30.34)$ & 0.99 \\
\hline \multicolumn{4}{|l|}{ MUFAs } \\
\hline C16:1 ( $\mu \mathrm{mol} / \mathrm{l}$ & $15.06(12.33 ; 21.72)$ & 14.56 (12.00; 19.79) & 0.60 \\
\hline $\mathrm{C} 18: 1(\mu \mathrm{mol} / \mathrm{l})$ & $270.77(244.27 ; 332.28)$ & $285.625(246.25 ; 336.565)$ & 0.75 \\
\hline \multicolumn{4}{|l|}{ n-3 PUFAs } \\
\hline C18:3; ALA ( $\mu \mathrm{mol} / \mathrm{l})$ & $5.75(4.73 ; 8.48)$ & $7.21(5.22 ; 8.94)$ & 0.26 \\
\hline C20:5; EPA $(\mu \mathrm{mol} / \mathrm{l})$ & $71.66(48.65 ; 90.31)$ & $48.55(38.96 ; 66.86)$ & 0.002 \\
\hline $\mathrm{C} 22: 6 ; \mathrm{DHA}(\mu \mathrm{mol} / \mathrm{l})$ & $303.11(241.62 ; 355.04)$ & $263.25(208.77 ; 325.18)$ & 0.07 \\
\hline \multicolumn{4}{|l|}{ n-6 PUFAs } \\
\hline C18:2; LA ( $\mu \mathrm{mol} / \mathrm{l})$ & $421.46(343.43 ; 476.27)$ & $471.02(402.46 ; 546.30)$ & 0.02 \\
\hline $\mathrm{C} 20: 2(\mu \mathrm{mol} / \mathrm{l})$ & $16.39(13.24 ; 18.33)$ & $18.21(14.39 ; 22.26)$ & 0.14 \\
\hline $\mathrm{C} 20: 4 ; \mathrm{AA}(\mu \mathrm{mol} / \mathrm{l})$ & $542.03 \pm 95.38$ & $561.92 \pm 154.30$ & 0.51 \\
\hline Total SFAs $(\mu \mathrm{mol} / \mathrm{l})$ & $1439.66 \pm 288.90$ & $1431.66 \pm 282.75$ & 0.90 \\
\hline Total MUFAs ( $\mu \mathrm{mol} / \mathrm{l})$ & $286.15(260.18 ; 356.12)$ & $308.95(261.43 ; 357.57)$ & 0.77 \\
\hline Total n-3 PUFAs $(\mu \mathrm{mol} / \mathrm{l})$ & $378.16(296.06 ; 436.75)$ & $320.70(260.36 ; 396.61)$ & 0.02 \\
\hline Total n-6 PUFAs ( $\mu \mathrm{mol} / \mathrm{l})$ & $986.24 \pm 171.11$ & $1065.54 \pm 210.49$ & 0.08 \\
\hline Total FAs $(\mu \mathrm{mol} / \mathrm{l})$ & $3088.55(2785.20 ; 3413.38)$ & $3148.76(2748.18 ; 3519.32)$ & 0.65 \\
\hline n-6/n-3 ratio ${ }^{a}$ & $2.69 \pm 0.78$ & $3.32 \pm 0.83$ & 0.001 \\
\hline EPA/AA ratio & $0.13(0.07 ; 0.14)$ & $0.10(0.07 ; 0.12)$ & 0.008 \\
\hline DHA/AA ratio & $0.13(0.09 ; 0.17)$ & $0.50(0.41 ; 0.59)$ & 0.15 \\
\hline
\end{tabular}

Data are given as number (percentage) for categorical variables and mean ( \pm standard deviation) or median (IQR) for continuous variables Italic values indicate significance of $\mathrm{p}$ value $(\mathrm{p}<0.05)$

$A A$ arachidonic acid, ALA alpha-linolenic acid, DHA docosahexaenoic acid, EPA eicosapentaenoic acid, FAs fatty acids, LA linoleic acid, MUFAs monounsaturated fatty acids, PUFAs polyunsaturated fatty acids, SFAs saturated fatty acids

a The $n-6 / n-3$ fatty acid ratio was calculated by measuring: linoleic, C18:2n-6; eicosadienoic, C20:2n-6; arachidonic, C20:4n-6 acids to estimate total n- 6 PUFAs and alpha-linolenic, C18:3n-3; eicosapentaenoic, C20:5n-3; docosahexaenoic, C22:6n-3 acids to estimate the total n-3 PUFAs

Table 4 Univariate and multivariate logistic regression analysis of poor glycemic control ( $\mathrm{HbA}_{1 \mathrm{c}} \geq \mathbf{7 . 0 \% )}$ in the study patients

\begin{tabular}{|c|c|c|c|c|}
\hline \multirow[t]{2}{*}{ Variable } & \multicolumn{2}{|l|}{ Univariate analysis } & \multicolumn{2}{|c|}{ Multivariate analysis } \\
\hline & OR $(95 \% \mathrm{Cl})$ & $p$ value & OR $(95 \% \mathrm{Cl})$ & $p$ value \\
\hline Insulin therapy & $5.70(2.08-15.67)$ & $<0.001$ & & \\
\hline$n-6 / n-3$ ratio & $2.69(1.41-5.14)$ & 0.003 & $4.35(1.72-10.96)$ & 0.002 \\
\hline hsCRP (mg/l) & $1.28(1.01-1.62)$ & 0.043 & $1.52(1.04-2.21)$ & 0.032 \\
\hline Total n-6 PUFAs ( $\mu \mathrm{mol} / \mathrm{l})$ & $1.25(1.04-1.50)$ & 0.020 & & \\
\hline T2DM duration (years) & $1.11(1.02-1.21)$ & 0.019 & $1.18(1.04-1.32)$ & 0.008 \\
\hline C18:2; LA ( $\mu \mathrm{mol} / \mathrm{I})$ & $1.01(1.001-1.011)$ & 0.037 & & \\
\hline C20:5; EPA $(\mu \mathrm{mol} / \mathrm{l})$ & $0.98(0.97-1.00)$ & 0.050 & & \\
\hline Total n-3 PUFAs ( $\mu \mathrm{mol} / \mathrm{l})$ & $0.76(0.63-0.93)$ & 0.007 & & \\
\hline C-peptide (ng/ml) & $0.66(0.45-0.96)$ & 0.028 & & \\
\hline EPA/AA ratio & $0.001(0.0001-0.51)$ & 0.034 & & \\
\hline
\end{tabular}

$A A$ arachidonic acid, $C l$ confidence interval, EPA eicosapentaenoic acid, $H b A_{1 c}$ glycated hemoglobin, $h s C R P$ high-sensitivity $C$-reactive protein, $L A$ linoleic acid, $P U F A s$ polyunsaturated fatty acids, $O R$ odds ratio, T2DM type 2 diabetes mellitus 
levels of n-6 PUFAs in plasma phospholipids, in particular LA, are linked to a lower risk of T2DM $[29,37]$.

On the other hand, some epidemiological studies and animal models suggest that $n-6$ PUFAs may promote adiposity and influence metabolic processes in various tissues [38]. There are a number of ways by which $n-6$ PUFAs can adversely affect metabolic pathways: (1) promoting tissue AA accumulation and increased production of pro-inflammatory eicosanoids, (2) reduced conversion of ALA into EPA, (3) reduced production of anti-inflammatory eicosanoids from EPA and DHA [39]. It has been suggested that n-6 PUFAs incorporated into phospholipids may be more susceptible to oxidative stress compared to n-3 PUFAs [24]. In addition, the oxidized metabolites of LA (OXLAMs), including bioactive 9 - and 13 hydroxy-octadecadienoic acid (9- and 13-HODE) and 9- and 13-oxo-octadecadienoic acid (9- and 13-oxoODE), exert several pro-inflammatory and pro-atherogenic properties [40]. Some studies showed that higher plasma phospholipid n-6 PUFAs were associated with increased arterial stiffness as measured by carotidfemoral pulse wave velocity (cfPWV) [41, 42]. There is accumulating evidence from randomized controlled trials that replacement of dietary saturated FAs by LA significantly lowers serum total cholesterol (mostly by reducing low-density lipoprotein cholesterol) but does not support the hypothesis that this translates to a lower risk of death from CAD or decreased all-cause mortality [40].

Furthermore, it has been reported that LA intake was inversely associated with leukocyte telomere length (LTL) in female participants of the Nurses' Health Study [43]. As an indicator of oxidative stress, DNA damage and cellular senescence, LTL has been postulated as a biomarker of aging and age-related chronic diseases, including CAD and T2DM $[43,44]$.

In our study, elevated levels of LA in serum phospholipids of patients with poor glycemic control could be caused by higher dietary intake of LA/lower frequency of meals or by altered pathways of n-6 PUFA metabolism. Unfortunately, we did not conduct a dietary survey in our patients. However, all participants were consulted by a cardiovascular physician and each patient received the same diet recommendations consistent with the European Society of Cardiology guidelines. Therefore, it seems unlikely, that the study patients with worse glycemic control had a different diet, particularly rich in linoleic acid, what could possibly result in higher concentrations of linoleic acid in serum phospholipids. We believe that higher serum phospholipid linoleic acid levels in patients with poor glycemic control could result from altered $n-6$ PUFA metabolism. As the parent compound for the family of n-6 PUFAs, LA can be elongated and desaturated to other n-6 PUFAs, such as $\gamma$-linolenic acid and AA. It has been reported that in diabetes, the fatty acid elongase and desaturase (i.e. $\Delta 5$ - and $\Delta 6$-desaturase) activities decrease significantly, which may result in altered levels of PUFAs among patients with metabolic syndrome and T2DM $[13,45]$. The desaturase enzymes are also regulated and modulated by many dietary and hormonal factors, including insulin $[13,45]$. However, exogenous insulin does not seem to significantly influence phospholipid FA composition and desaturase activities in patients with T2DM [13].

As previously reported, a high intake of LA may disturb the metabolism and distribution of n-3 PUFAs [38]. It is well known that both LA and ALA compete for the same active site of microsomal $\Delta 6$-desaturase, the ratelimiting enzyme in long-chain PUFA biosynthesis [27]. It is possible that higher serum phospholipid LA concentrations in patients with poor glycemic control contribute to decrease of ALA metabolism and reduced synthesis of EPA and DHA, resulting in increased $n-6 / n-3$ ratio.

\section{PUFAs and systemic inflammation}

Numerous epidemiological and clinical studies showed that the high intake of n-3 PUFAs is associated with decreased inflammation [14]. Low-grade systemic inflammation as measured by serum concentrations of CRP is related to insulin resistance and ASCVD [46]. However, a potential mediating role of low-grade inflammation in the association between FA composition and insulin resistance is still unclear [46].

It has been suggested that $n-3$ and n-6 PUFAs cause opposite effects on systemic inflammation [34]. The eicosanoids derived from n-3 PUFAs generally have antiinflammatory properties, while n- 6 PUFA-derived lipid mediators are considered pro-inflammatory $[47,48]$. LA is a precursor of AA, which may be converted to the proinflammatory prostaglandin $\mathrm{E}_{2}\left(\mathrm{PGE}_{2}\right)$ and leukotriene $\mathrm{B}_{4}$ [18]. On the contrary, eicosanoids derived from the EPA can down-regulate the biosynthesis of $\mathrm{PGE}_{2}$ [18]. The anti-inflammatory effects of n-3 PUFAs are related, in large part, to competition between EPA and AA as substrates for cyclooxygenases and to prevention of the conversion of AA into potent pro-inflammatory eicosanoids [18]. Thus, a high $n-6 / n-3$ ratio may promote inflammatory diseases including ASCVD $[16,18]$. The EPA/AA and DHA/AA ratios may reflect cardiovascular inflammation in patients with ASCVD and remain established markers of cardiovascular events [16].

Furthermore, n-3 PUFAs can serve as alternative substrates to produce less potent mediators, including 3 -series prostaglandins and thromboxanes, and 5-series leukotrienes [18]. Experimental studies showed that EPA and DHA are also substrates for production of proresolving lipid mediators such as resolvins, maresins and protectins [18]. There is accumulating evidence that these bioactive compounds can influence glucose and insulin 
homeostasis and directly exert cardioprotective actions in vivo [18].

Serum concentrations of CRP in Western populations have been positively associated with some saturated (e.g. stearic acid) and monounsaturated FAs (e.g. palmitoleic and oleic acids), but inversely associated with LA and n-3
PUFAs such as ALA and EPA [49]. Kaska et al. found that both total saturated and monounsaturated FAs are positively correlated with serum hsCRP, whereas both $\mathrm{n}-6$ and n-3 PUFAs show inverse correlation with this marker in patients with $\mathrm{HbA}_{1 \mathrm{c}}$ levels $<7.0 \%$ [48].
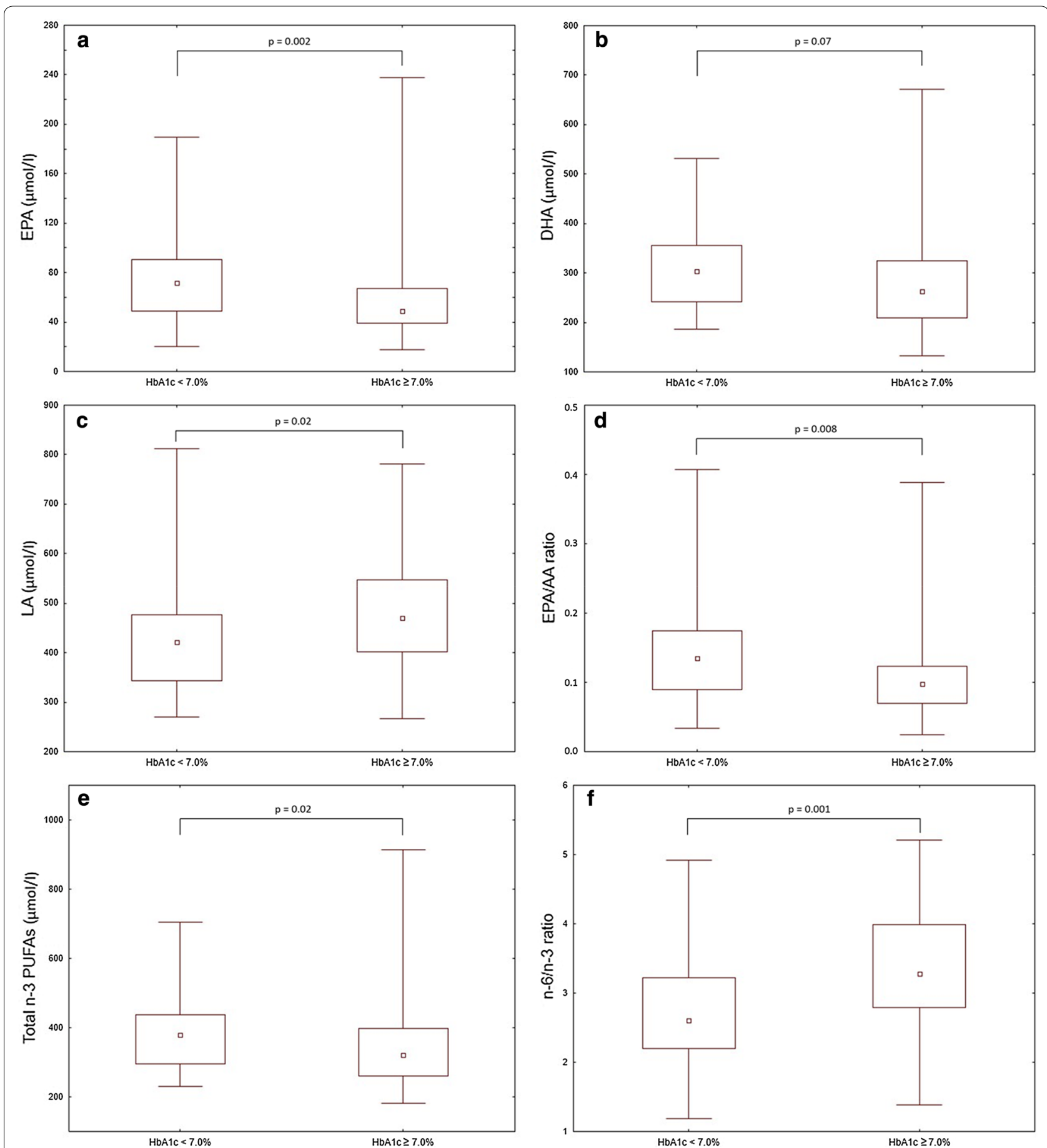

Fig. 1 Eicosapentaenoic acid (EPA) concentration (a), docosahexaenoic acid (DHA) concentration (b), linoleic acid (LA) concentration (c), EPA to arachidonic acid (EPA/AA) ratio (d), total n-3 PUFAs concentration (e), and n-6 to n-3 PUFA ratio (f) in serum phospholipids of the study patients 
In addition, Poudel-Tandukar et al. demonstrated that CRP levels in a Japanese working population increased with a decreasing proportion of ALA and an increasing proportion of palmitic acid in men, and with an increasing proportion of dihomo- $\gamma$-linolenic acid in both sexes [49]. Similarly, studies among European populations have also disclosed an inverse association between serum ALA and CRP concentrations [49].

In our study, however, levels of saturated, monounsaturated and polyunsaturated fatty acids in serum phospholipids were not significantly associated with systemic inflammatory markers.

\section{Limitations}

Our study has several limitations. First, the cross-sectional nature of the study did not allow us to infer causality. Second, the dietary fat intake was not assessed precisely, as our participants were provided dietary advice regarding low-fat and low-carbohydrate foods and caloric values. Therefore, we cannot unambiguously exclude the influence of a diet on the observed results. Finally, the sample size was relatively small in the present study and a larger sample would have provided more robust findings.

\section{Conclusions}

In conclusion, this study showed that glycemic control in high-risk T2DM patients with ASCVD was significantly associated with unfavorable serum phospholipid n-6/n-3 PUFA ratio and greater systemic inflammation. There was no relevant relationship between serum phospholipid FA composition and systemic inflammation. These results confirm the beneficial effect of long-chain n-3 PUFAs in T2DM and support current recommendations for regular fish consumption.

\begin{abstract}
Abbreviations
AA: arachidonic acid; ACE: angiotensin-converting enzyme; ALA: alphalinolenic acid; ARB: angiotensin II receptor blocker; ASA: acetylsalicylic acid; ASCVD: atherosclerotic cardiovascular disease; CAD: coronary artery disease; $\mathrm{Cl}$ : confidence interval; DHA: docosahexaenoic acid; EPA: eicosapentaenoic acid; FAs: fatty acids; $\mathrm{HbA}_{1}$ : glycated hemoglobin; $\mathrm{HDL}-\mathrm{C}$ : high-density lipoproteins; hsCRP: high-sensitivity C-reactive protein; IL-6: interleukin-6; LA: linoleic acid; LDL-C: low-density lipoproteins; MI: myocardial infarction; MRA: mineralocorticoid receptor antagonist; MUFAs: monounsaturated fatty acids; OR: odds ratio; PAD: peripheral arterial disease; PCl: percutaneous coronary intervention; $\mathrm{PGE}_{2}$ : prostaglandin $\mathrm{E}_{2}$; PPI: proton pump inhibitor; PUFAs: polyunsaturated fatty acids; SFAs: saturated fatty acids; TC: total cholesterol; Tg: triglycerides; TNFa: tumour necrosis factor a; T2DM: type 2 diabetes mellitus.
\end{abstract}

\footnotetext{
Authors' contributions

MP, PR contributed to the work by acquisition of data, analysis and interpretation of data, as well as writing and revision of the manuscript. AS, MM, RG-W contributed to the work by acquisition and analysis of data. JN contributed to the work by analysis of data and revision of the manuscript. AU contributed to the work by performing most of laboratory testing and revision of the manuscript. GG made substantial contributions to conception and design of the study, analysis and interpretation of data, revision of the manuscript and
}

final approval of the version to be published. All authors read and approved the final manuscript.

\section{Author details \\ ${ }^{1}$ Department of Coronary Disease and Heart Failure, Faculty of Medicine, Jagiellonian University Medical College, The John Paul II Hospital, 80 Pradnicka Street, 31-202 Kraków, Poland. ${ }^{2}$ Institute of Cardiology, Faculty of Medicine, Jagiellonian University Medical College, The John Paul II Hospital, Kraków, Poland.}

\section{Acknowledgements}

Not applicable.

\section{Competing interests}

The authors declare that they have no competing interests.

\section{Availability of data and materials}

The datasets used and analyzed during the current study are available from the corresponding author on reasonable request.

\section{Consent for publication}

Not applicable.

\section{Ethics approval and consent to participate}

The study complied with the principles of the Good Clinical Practice International Conference on Harmonization rules and was approved by the Jagiellonian University Ethics Committee-No. KBET/190/B/2012; 31 May 2012. Each study participant provided written informed consent.

\section{Funding}

The study was supported by research grants: 2011/03/B/NZ5/0576 from the National Science Centre, Poland (to G.G.) and K/ZDS/005642 from the JagielIonian University Medical College (to G.G.).

\section{Publisher's Note}

Springer Nature remains neutral with regard to jurisdictional claims in published maps and institutional affiliations.

Received: 27 November 2017 Accepted: 3 February 2018

Published online: 16 February 2018

\section{References}

1. American Diabetes Association. 9. Cardiovascular disease and risk management. Diabetes Care. 2017;40(Suppl 1):S75-87.

2. Gajos G, Piłaciński S, Zozulińska-Ziółkiewicz D. Controversies in diabetes in 2013-a brief update. Adv Clin Exp Med. 2013;22:777-84.

3. Schnell O, Rydén L, Standl E, Ceriello A, D\&CVD EASD Study Group. Updates on cardiovascular outcome trials in diabetes. Cardiovasc Diabetol. 2017;16:128.

4. Low Wang CC, Hess CN, Hiatt WR, Goldfine AB. Clinical update: cardiovascular disease in diabetes mellitus: atherosclerotic cardiovascular disease and heart failure in type 2 diabetes mellitus-mechanisms, management, and clinical considerations. Circulation. 2016:133:2459-502.

5. Laakso M. Cardiovascular disease in type 2 diabetes from population to man to mechanisms: the Kelly West Award Lecture 2008. Diabetes Care. 2010;33:442-9.

6. Gajos G, Konieczynska M, Zalewski J, Undas A. Low fasting glucose is associated with enhanced thrombin generation and unfavorable fibrin clot properties in type 2 diabetic patients with high cardiovascular risk. Cardiovasc Diabetol. 2015;14:44.

7. Gajos G, Mostowik M. Low blood glucose in type 2 diabetes: a lot more to come? Pol Arch Med Wewn. 2016;126:1019-20.

8. Piątkiewicz P, Buraczewska-Leszczyńska B, Kuczerowski R, BernatKarpińska M, Rabijewski M, Kowrach M. Severe hypoglycaemia in elderly patients with type 2 diabetes and coexistence of cardiovascular history. Kardiol Pol. 2016;74:779-85. 
9. Gumprecht J, Nabrdalik K. Hypoglycemia in patients with insulin-treated diabetes. Pol Arch Med Wewn. 2016;126:870-8.

10. Ebtehaj S, Gruppen EG, Parvizi M, Tietge UJF, Dullaart RPF. The anti-inflammatory function of $\mathrm{HDL}$ is impaired in type 2 diabetes: role of hyperglycemia, paraoxonase-1 and low grade inflammation. Cardiovasc Diabetol. 2017;16:132.

11. Małecki M, Kozek E, Zozulińska-Ziółkiewicz D, Kopeć G, Knap K, Sarnecka A, et al. Polish forum for prevention guidelines on diabetes: update 2017. Kardiol Pol. 2017;75:628-31.

12. Cavender MA, Scirica BM, Raz I, Steg PG, McGuire DK, Leiter LA, et al. Cardiovascular outcomes of patients in SAVOR-TIMI 53 by baseline hemoglobin A1c. Am J Med. 2016;129:340.e1-8.

13. Sartore G, Lapolla A, Reitano R, Zambon S, Romanato G, Marin R, et al. Desaturase activities and metabolic control in type 2 diabetes. Prostaglandins Leukot Essent Fatty Acids. 2008;79:55-8.

14. Salas-Salvadó J, Martinez-González MÁ, Bulló M, Ros E. The role of diet in the prevention of type 2 diabetes. Nutr Metab Cardiovasc Dis. 2011;21(Suppl 2):B32-48.

15. Leeson CP, Mann A, Kattenhorn M, Deanfield JE, Lucas A, Muller DP. Relationship between circulating $n-3$ fatty acid concentrations and endothelial function in early adulthood. Eur Heart J. 2002;23:216-22.

16. Takahashi M, Ando J, Shimada K, Nishizaki Y, Tani S, Ogawa T, et al. The ratio of serum n-3 to $n-6$ polyunsaturated fatty acids is associated with diabetes mellitus in patients with prior myocardial infarction: a multicenter cross-sectional study. BMC Cardiovasc Disord. 2017;17:41.

17. Gajos G, Rostoff P, Undas A, Piwowarska W. Effects of polyunsaturated omega-3 fatty acids on responsiveness to dual antiplatelet therapy in patients undergoing percutaneous coronary intervention: the OMEGAPCI (OMEGA-3 fatty acids after pci to modify responsiveness to dual antiplatelet therapy) study. J Am Coll Cardiol. 2010;55:1671-8.

18. Endo J, Arita M. Cardioprotective mechanism of omega-3 polyunsaturated fatty acids. J Cardiol. 2016;67:22-7.

19. Makarewicz-Wujec M, Parol G, Parzonko A, Kozłowska-Wojciechowska M. Supplementation with omega-3 acids after myocardial infarction and modification of inflammatory markers in light of the patients' diet: a preliminary study. Kardiol Pol. 2017;75:674-81.

20. Siscovick DS, Barringer TA, Fretts AM, Wu JH, Lichtenstein AH, Costello $\mathrm{RB}$, American Heart Association Nutrition Committee of the Council on Lifestyle and Cardiometabolic Health, Council on Epidemiology and Prevention, Council on Cardiovascular Disease in the Young, Council on Cardiovascular and Stroke Nursing, Council on Clinical Cardiology, et al. Omega-3 polyunsaturated fatty acid (fish oil) supplementation and the prevention of clinical cardiovascular disease: a science advisory from the American Heart Association. Circulation. 2017:135:e867-84.

21. ORIGIN Trial Investigators, Bosch J, Gerstein HC, Dagenais GR, Díaz R, Jung $\mathrm{H}$, et al. n-3 Fatty acids and cardiovascular outcomes in patients with dysglycemia. N Engl J Med. 2012;367:309-18.

22. Poreba M, Mostowik M, Siniarski A, Golebiowska-Wiatrak R, Malinowski KP, Haberka M, et al. Treatment with high-dose n-3 PUFAs has no effect on platelet function, coagulation, metabolic status or inflammation in patients with atherosclerosis and type 2 diabetes. Cardiovasc Diabetol. 2017;16:50.

23. Cho JS, Baek SH, Kim JY, Lee JH, Kim OY. Serum phospholipid monounsaturated fatty acid composition and $\Delta$-9-desaturase activity are associated with early alteration of fasting glycemic status. Nutr Res. 2014;34:733-41.

24. Kahleova H, Malinska H, Kazdova L, Belinova L, Tura A, Hill M, et al. The effect of meal frequency on the fatty acid composition of serum phospholipids in patients with type 2 diabetes. J Am Coll Nutr. 2016:35:317-25.

25. Kurotani K, Sato M, Ejima Y, Nanri A, Yi S, Pham NM, et al. High levels of stearic acid, palmitoleic acid, and dihomo-y-linolenic acid and low levels of linoleic acid in serum cholesterol ester are associated with high insulin resistance. Nutr Res. 2012;32(669-675):e3.

26. Albert BB, Derraik JG, Brennan CM, Biggs JB, Smith GC, Garg ML, et al. Higher omega-3 index is associated with increased insulin sensitivity and more favourable metabolic profile in middle-aged overweight men. Sci Rep. 2014;4:6697.

27. Flachs P, Rossmeisl M, Kopecky J. The effect of $n-3$ fatty acids on glucose homeostasis and insulin sensitivity. Physiol Res. 2014;63(Suppl 1):S93-118.
28. Virtanen JK, Mursu J, Voutilainen S, Uusitupa M, Tuomainen TP. Serum omega-3 polyunsaturated fatty acids and risk of incident type 2 diabetes in men: the Kuopio Ischemic Heart Disease Risk Factor study. Diabetes Care. 2014;37:189-96.

29. Forouhi NG, Imamura F, Sharp SJ, Koulman A, Schulze MB, Zheng J, et al. Association of plasma phospholipid $n-3$ and $n-6$ polyunsaturated fatty acids with type 2 diabetes: the EPIC-InterAct Case-Cohort Study. PLoS Med. 2016;13:e1002094.

30. Li D. Omega-3 polyunsaturated fatty acids and non-communicable diseases: meta-analysis based systematic review. Asia Pac J Clin Nutr. 2015:24:10-5.

31. Coelho OG, da Silva BP, Rocha DM, Lopes LL, Alfenas RCG. Polyunsaturated fatty acids and type 2 diabetes: impact on the glycemic control mechanism. Crit Rev Food Sci Nutr. 2017;57:3614-9.

32. Kusunoki M, Tsutsumi K, Nakayama M, Kurokawa T, Nakamura T, Ogawa H, et al. Relationship between serum concentrations of saturated fatty acids and unsaturated fatty acids and the homeostasis model insulin resistance index in Japanese patients with type 2 diabetes mellitus. J Med Investig. 2007:54:243-7.

33. Sawada T, Tsubata H, Hashimoto N, Takabe M, Miyata T, Aoki K, et al. Effects of 6-month eicosapentaenoic acid treatment on postprandial hyperglycemia, hyperlipidemia, insulin secretion ability, and concomitant endothelial dysfunction among newly-diagnosed impaired glucose metabolism patients with coronary artery disease. An open label, single blinded, prospective randomized controlled trial. Cardiovasc Diabetol. 2016;15:121.

34. Simopoulos AP. The importance of the omega- $6 /$ omega- 3 fatty acid ratio in cardiovascular disease and other chronic diseases. Exp Biol Med. 2008:233:674-88.

35. Husted KS, Bouzinova EV. The importance of $n-6 / n-3$ fatty acids ratio in the major depressive disorder. Medicina. 2016;52:139-47.

36. Rosqvist F, Bjermo H, Kullberg J, Johansson L, Michaëlsson K, Ahlström H, et al. Fatty acid composition in serum cholesterol esters and phospholipids is linked to visceral and subcutaneous adipose tissue content in elderly individuals: a cross-sectional study. Lipids Health Dis. 2017;16:68.

37. Wu JHY, Marklund M, Imamura F, Tintle N, Ardisson Korat AV, de Goede J, et al. Omega- 6 fatty acid biomarkers and incident type 2 diabetes: pooled analysis of individual-level data for 39740 adults from 20 prospective cohort studies. Lancet Diabetes Endocrinol. 2017;5:965-74.

38. Vinknes KJ, Elshorbagy AK, Drevon CA, Nurk E, Tell GS, Nygård O, et al. Associations between plasma polyunsaturated fatty acids, plasma stearoyl-CoA desaturase indices and body fat. Obesity. 2013;21:E512-9.

39. Fritsche KL. The science of fatty acids and inflammation. Adv Nutr. 2015;6:293S-301S.

40. Ramsden CE, Zamora D, Majchrzak-Hong S, Faurot KR, Broste SK, Frantz $\mathrm{RP}$, et al. Re-evaluation of the traditional diet-heart hypothesis: analysis of recovered data from Minnesota Coronary Experiment (1968-73). BMJ. 2016:353:11246.

41. Tomiyama H, Matsumoto C, Odaira M, Yamada J, Yoshida M, Shiina K, et al. Relationships among the serum omega fatty acid levels, serum C-reactive protein levels and arterial stiffness/wave reflection in Japanese men. Atherosclerosis. 2011;217:433-6.

42. Reinders I, Murphy RA, Song X, Mitchell GF, Visser M, Cotch MF, et al. Higher plasma phospholipid n-3 PUFAs, but lower n-6 PUFAs, are associated with lower pulse wave velocity among older adults. J Nutr. 2015;145:2317-24.

43. Cassidy A, De Vivo I, Liu Y, Han J, Prescott J, Hunter DJ, et al. Associations between diet, lifestyle factors, and telomere length in women. Am J Clin Nutr. 2010;91:1273-80.

44. Mazidi M, Kengne AP, Banach M. Mineral and vitamin consumption and telomere length among adults in the United States. Pol Arch Intern Med. 2017:127:87-90.

45. Whelan J, Fritsche K. Linoleic acid. Adv Nutr. 2013;4:311-2.

46. Petersson H, Basu S, Cederholm T, Risérus U. Serum fatty acid composition and indices of stearoyl-CoA desaturase activity are associated with systemic inflammation: Iongitudinal analyses in middle-aged men. $\mathrm{Br}$ 」 Nutr. 2008;99:1186-9.

47. Sanak M, Plutecka H, Szczeklik W, Piwowarska W, Rostoff P, Szczeklik A. Functional promoter polymorphism of cyclooxygenase-2 modulates the inflammatory response in stable coronary heart disease. Pol Arch Med Wewn. 2010;120:82-8. 
48. Kaska L, Mika A, Stepnowski P, Proczko M, Ratnicki-Sklucki K, Sledzinsk $T$, et al. The relationship between specific fatty acids of serum lipids and serum high sensitivity C-reactive protein levels in morbidly obese women. Cell Physiol Biochem. 2014;34:1101-8.
49. Poudel-Tandukar K, Sato M, Ejima Y, Nanri A, Matsushita Y, Imaizumi K, et al. Relationship of serum fatty acid composition and desaturase activity to C-reactive protein in Japanese men and women. Atherosclerosis. 2012;220:520-4.
Submit your next manuscript to BioMed Central and we will help you at every step:

- We accept pre-submission inquiries

- Our selector tool helps you to find the most relevant journal

- We provide round the clock customer support

- Convenient online submission

- Thorough peer review

- Inclusion in PubMed and all major indexing services

- Maximum visibility for your research

Submit your manuscript at www.biomedcentral com/submit
() Biomed Central 